\title{
DNA methylation during human adipogenesis and the impact of fructose
}



Giulia Tini ${ }^{1,2,3}$, Vijayalakshmi Varma ${ }^{4,5}$, Rosario Lombardo ${ }^{1}$, Greg T. Nolen ${ }^{4}$, Gregory Lefebvre ${ }^{6}$, Patrick Descombes ${ }^{6}$, Sylviane Métairon ${ }^{6}$, Corrado Priami ${ }^{1,7}$, Jim Kaput ${ }^{6,8}$ and Marie-Pier Scott-Boyer ${ }^{1,9^{*}}$

\begin{abstract}
Background: Increased adipogenesis and altered adipocyte function contribute to the development of obesity and associated comorbidities. Fructose modified adipocyte metabolism compared to glucose, but the regulatory mechanisms and consequences for obesity are unknown. Genome-wide methylation and global transcriptomics in SGBS pre-adipocytes exposed to $0,2.5,5$, and $10 \mathrm{mM}$ fructose, added to a 5-mM glucose-containing medium, were analyzed at 0, 24, 48, 96, 192, and $384 \mathrm{~h}$ following the induction of adipogenesis.

Results: Time-dependent changes in DNA methylation compared to baseline $(0 \mathrm{~h})$ occurred during the final maturation of adipocytes, between 192 and $384 \mathrm{~h}$. Larger percentages (0.1\% at $192 \mathrm{~h}, 3.2 \%$ at $384 \mathrm{~h}$ ) of differentially methylated regions (DMRs) were found in adipocytes differentiated in the glucose-containing control media compared to adipocytes differentiated in fructose-supplemented media $(0.0006 \%$ for $10 \mathrm{mM}, 0.001 \%$ for $5 \mathrm{mM}$, and $0.005 \%$ for $2.5 \mathrm{mM}$ at $384 \mathrm{~h}$ ). A total of 1437 DMRs were identified in 5237 differentially expressed genes at $384 \mathrm{~h}$ post-induction in glucose-containing $(5 \mathrm{mM})$ control media. The majority of them inversely correlated with the gene expression, but 666 regions were positively correlated to the gene expression.

Conclusions: Our studies demonstrate that DNA methylation regulates or marks the transformation of morphologically differentiating adipocytes (seen at $192 \mathrm{~h}$ ), to the more mature and metabolically robust adipocytes (as seen at $384 \mathrm{~h}$ ) in a genome-wide manner. Lower $(2.5 \mathrm{mM})$ concentrations of fructose have the most robust effects on methylation compared to higher concentrations ( 5 and $10 \mathrm{mM}$ ), suggesting that fructose may be playing a signaling/regulatory role at lower concentrations of fructose and as a substrate at higher concentrations.
\end{abstract}

Keywords: Adipocyte differentiation, DNA methylation, Differentially methylated regions, Gene expression, Integration analysis, Obesity

\section{Background}

Obesity and its comorbidities are growing worldwide epidemics [83]. A major component of modern, Westernized nutrition is the consumption of highly refined sugar [48] that has been associated to the increasing incidence of metabolic disorders [33, 45]. While overnutrition by consuming added sucrose remains the focus of more than

\footnotetext{
* Correspondence: MariePier.ScottBoyer@crchudequebec.ulaval.ca

'The Microsoft Research - University of Trento Centre for Computational and Systems Biology, Piazza Manifattura 1, 38068 Rovereto, Italy

9Present Address: CRCHU de Québec-Université Laval, Quebec City, Québec, Canada

Full list of author information is available at the end of the article
}

100 years of research, the sharp rise in obesity and diabetes since the introduction of high-fructose corn syrup (HFCS) to manufactured foods directed attention to the role of fructose in metabolism and disease development [30]. The most recent meta-analysis of 13 studies with a combined total of 49,591 participants and over 14,000 cases showed a linear association between fructose intake and metabolic syndrome (MetS). However, this adverse correlation was specific to sugar-sweetened beverages (SSB) [60] and not other fructose-containing foods (e.g., yogurt, whole fruits) indicating that the food matrix plays a significant (and expected) role in the metabolism of nutrients. Fructose metabolism and the consequent effects

(c) The Author(s). 2020 Open Access This article is licensed under a Creative Commons Attribution 4.0 International License, which permits use, sharing, adaptation, distribution and reproduction in any medium or format, as long as you give appropriate credit to the original author(s) and the source, provide a link to the Creative Commons licence, and indicate if changes were made. The images or other third party material in this article are included in the article's Creative Commons licence, unless indicated otherwise in a credit line to the material. If material is not included in the article's Creative Commons licence and your intended use is not permitted by statutory regulation or exceeds the permitted use, you will need to obtain permission directly from the copyright holder. To view a copy of this licence, visit http://creativecommons.org/licenses/by/4.0/. 
on the regulation of host energy balance have been extensively studied in the gastrointestinal tract, kidney, and liver $[25,64]$. Human, laboratory animal, and cell culture systems have also demonstrated that fructose can be metabolized in the hypothalamus [9], innate immune system [83], cardiac and skeletal muscles ([25, 64], and adipose tissue and cells $[25,64]$. Excess fructose intake leads to the development of the multiple features of metabolic syndrome [7] including fatty liver, insulin resistance, diabetes, obesity, and hypertension [25].

Adipose tissue is a key node in the physiological system of health and disease development since it stores excess energy in the form of triglyceride through (i) an increase of adipocyte size (hypertrophy) and (ii) the promotion of differentiation or adipogenesis of pre-existing adipocytes (hyperplasia) [10]. Obesity occurs as a consequence of a chronic positive energy intake which brings hypertrophy to a plateau resulting in the promotion of hyperplasia to manage with unbalance energy intakes [10]. Early research identified the peroxisomal proliferator activate receptors $\gamma$ (PPAR $\gamma$ ) and CCAAT/enhancer binding protein $\alpha(\mathrm{C} / \mathrm{EBP} \alpha)$ as the master regulators of adipogenesis. The use of gene knockouts or knockdowns in cell culture and laboratory animals has greatly expanded the knowledge of the transcription factors, chromatin (re) modeling proteins (e.g., histones, sirtuins) and enzymes (protein acetyltransferases/deacetyltransferase and methylases/demethylases), microRNAs, and DNA methylation/demethylations that are involved in control of adipogenesis [37]. Time course experiments also demonstrated the changes in transcriptional regulation and protein-protein interaction networks that occur during differentiation from pre-adipocytes to adipocytes [51].

The role of DNA methylation has been the main focus of the control of gene expression because it had previously been thought to be a "stable" epigenetic mark. DNA methyltransferases (DNMTs) transfer the methyl group from $\mathrm{S}$-adenosylmethionine to the 5 position of the cytosine primarily in CpG dinucleotides forming 5methylcytosine (5mC) [31]. Methylation in CpG-enriched regions, called $\mathrm{CpG}$ islands, provides regulatory mechanisms of gene expression and is essential for cell differentiation and tissue integrity [3]. The effect of methylation on gene expression depends on where methylation occurs: high methylation levels in promoters normally repress gene transcription [38], while methylation within intronic and exonic regions of a gene body is positively correlated with expression [32]. DNA methylation can be affected by environmental factors such as lifestyle and diet, particularly by choline, betaine, folate, riboflavin, and vitamin B12 which are metabolized in the one-carbon cycle that produces S-adenosylmethionine, the primary methyl donor [8]. The relatively recent discovery that $5 \mathrm{mC}$ can be oxidized to 5-hydroxymethylcytosine (by ten-eleven translocation (TET) methylcytosine dioxygenase) as the first step in functional demethylation has revealed a more dynamic nature of DNA methylation [76].

Altered DNA methylation has been associated with chronic diseases linked to unbalanced diets such as obesity [3, 71], increased body mass index (BMI) [15], and hepatic steatosis [12]. In addition, a relationship between the methylation of genes involved in the circadian clock system and obesity, metabolic syndrome, and weight loss has been described [44].

The controversial link between increased consumption of fructose in human diets and the obesity epidemic [5] stimulated research that tested the detrimental impact of this carbohydrate on insulin resistance and adipocyte differentiation, two key processes to maintain metabolic health [36, 39]. The role of DNA methylation in fructose-induced metabolic syndrome and DNA methylation status in response to fructose has not been well characterized. Increased consumption of fructose has been shown to induce DNA methylation in PPAR $\alpha$ and CPT1A in rat liver [53], leading to reduced expression of these genes and then to a hepatic lipid accumulation. Fructose may alter adipocyte differentiation by increasing the levels of PPAR,$C / E B P \alpha$, and $F A B P 4$, at least in murine cells in culture [17]. While both fructose and glucose are substrates utilized to increase adiposity, fructose was shown to contribute more to weight gain in humans [63].

As a part of a series of studies examining the effects of fructose on adipocytes [70], we analyzed genome-wide transcriptomic and DNA methylation data at multiple time points during differentiation of the human Simpson-Golabi-Behmel syndrome (SGBS) euploid progenitor cells. Using an integrative approach (see Fig. 1), we identified genomic regions of differentially expressed genes where methylation of CpG sites differed compared to undifferentiated adipocytes.

\section{Results}

Genome-wide DNA methylation and transcriptomic during adipocyte differentiation

Genome-wide DNA methylation was measured using the Illumina $450 \mathrm{~K}$ BeadChip at different time points compared to baseline during adipocyte differentiation (see Table 1 for the study design).

The total number of genome-wide differentially methylated positions (DMPs) was identified as 8, 9, 16, 1904, and 116,637 at $24,48,96,192$, and $384 \mathrm{~h}$, respectively, while at the same time points, the genome-wide differentially methylated regions (DMRs) were 2, 2, 4, 607, and 15,573. The corresponding differential transcriptomic analysis identified 2007, 2473, 4977, 6594, and 5237 genes at those time points (Table 2). 


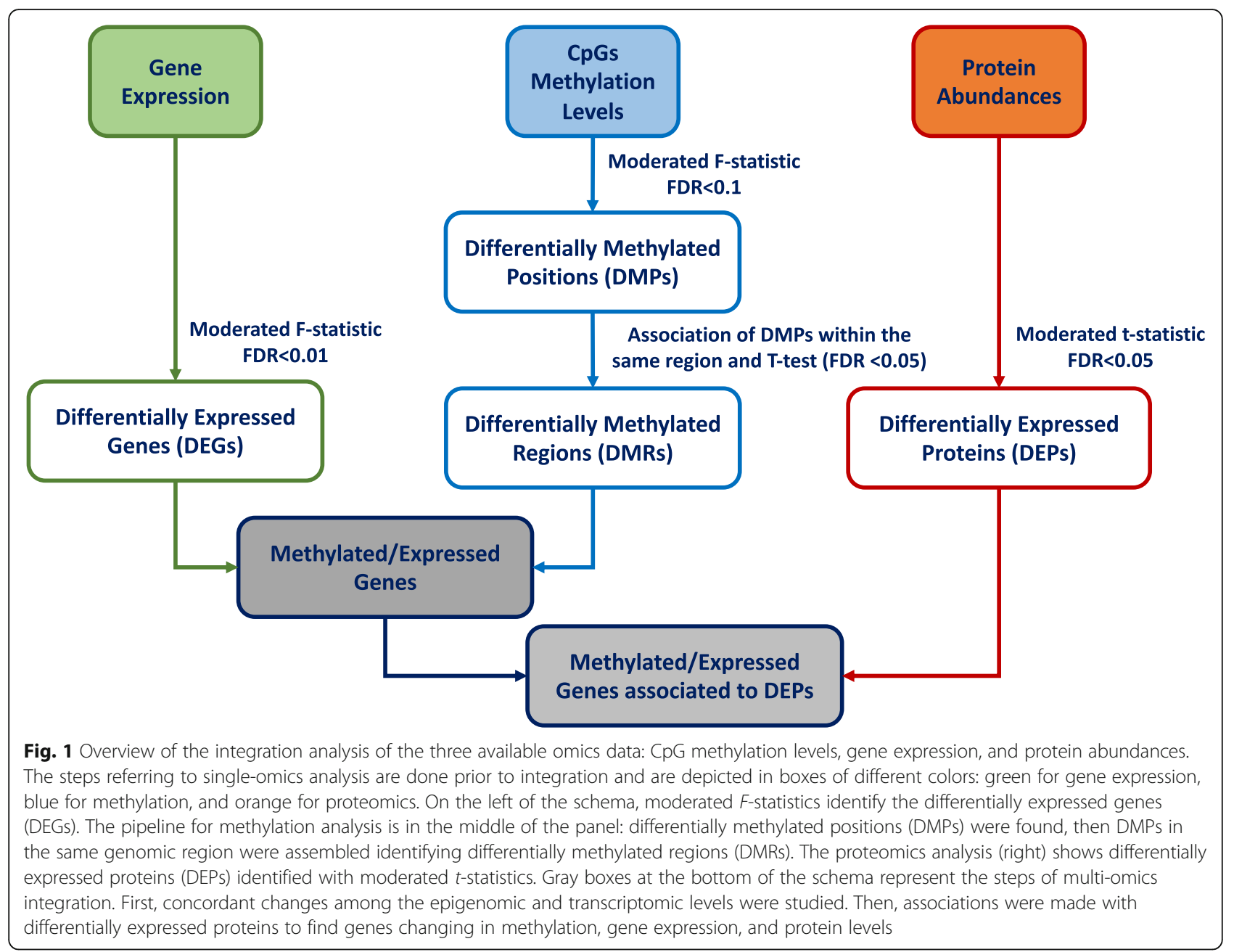

The integration of DNA methylation and transcriptomic data identified DMPs and DMRs in genes which were differentially expressed during adipocyte differentiation. The majority of methylated positions and gene regions did not change between pre-induction $(0 \mathrm{~h})$ and 24, 48, and $96 \mathrm{~h}$ after induction (Fig. 2a). However, a large number of changes in methylation were apparent at 192 and $384 \mathrm{~h}$ vs baseline (Fig. 2 and Table 2).

\section{Methylated region location in genes}

The location in the gene where DNA methylation occurs may differentially influence the gene expression [31]. At $192 \mathrm{~h}$, the majority of the changes in DNA methylation occurred in the promoter region (31 out of 57 DMRs [54.4\%]), while 18 genes (31.6\%) were methylated in exons and $8(14.0 \%)$ in introns (Table 3). At $384 \mathrm{~h}, 987$ DMRs $(68.7 \%$ of the total) were found in the promoter

Table 1 Summary of the study design. DNA methylation and gene expression were assayed at 6 different time points for control adipocytes, proteomics only at four time points ( 24 and $48 \mathrm{~h}$ excluded). DNA methylation, gene expression, and proteins changes in the fructose-treated adipocytes were examined at 192 and $384 \mathrm{~h}$, following the addition of 3 different doses of fructose (2.5 mM, 5 $\mathrm{mM}, 10 \mathrm{mM}$ )

\begin{tabular}{llllll}
\hline Hours & Glucose $(\mathrm{mM})$ & Fructose $(\mathrm{mM})$ & Methylation & Gene expression & Proteomics \\
\hline 0 & 5 & 0 & $\checkmark$ & $\checkmark$ & - \\
$24(1$ day) & 5 & 0 & $\checkmark$ & $\checkmark$ & - \\
$48(2$ days $)$ & 5 & 0 & $\checkmark$ & $\checkmark$ & $\checkmark$ \\
$96(4$ days $)$ & 5 & 0 & $\checkmark$ & $\checkmark$ & $\checkmark$ \\
192 (8 days) & 5 & $0,2.5,5,10$ & $\checkmark$ & $\checkmark$ \\
$384(16$ days $)$ & 5 & $0,2.5,5,10$ & $\checkmark$ & $\checkmark$ \\
\hline
\end{tabular}


Table 2 Differentially methylated regions (DMRs) and differentially expressed genes (DEGs) at different time points across adipocyte differentiation in control adipocytes. The number of genes differentially expressed used for the integration, the number of genomewide DMPs, and the number of CpG sites (\# DMPs on DEGs) and regions (\# DMRs on DEGs) with a significant change in methylation levels are displayed for each comparison. DMRs on DEGs, as well as DMPs on DEGs, are detected only at 192 and $384 \mathrm{~h}$ following the initiation of differentiation

\begin{tabular}{lllllll}
\hline Time point (h) & \# DEGs & \# Genome-wide DMPs & \# Genome-wide DMRs & \# DMPs on DEGs & \# DMRs on DEGs & \# DMRs not on DEGs \\
\hline 24 & 2007 & 8 & 2 & - & - & 2 \\
48 & 2473 & 9 & 2 & - & - & 2 \\
96 & 4977 & 16 & 4 & - & - & 4 \\
192 & 6594 & 1904 & 607 & 144 & 57 & 550 \\
384 & 5237 & 116,637 & 15,573 & 11,979 & 1437 & 14,136 \\
\hline
\end{tabular}

of the genes, $272(18.9 \%)$ in exons, $159(11.1 \%)$ in introns, and $19(1.3 \%)$ in intergenic regions of genes (Table 4). The majority of the genes with differentially methylated promoter regions had decreased gene expression (e.g., up-methylation of promoter region relative to $0 \mathrm{~h}$ was associated with reduced gene expression), while most cases of methylation in exons or introns affected gene expression in the same direction at $384 \mathrm{~h}$. Surprisingly, half of the DMRs in genes had both significant differential up-methylation and up-gene expression. This regulation could possibly be explained by other epigenetics mechanisms such as histone or other chromatin protein modifications and complex transcriptional factor regulation. Additionally, most of the DMRs on differentially expressed genes (DEGs) showing low $\beta$ values at $384 \mathrm{~h}$ were found to be anti-correlated with the gene expression had (Supplementary Figure S3).

\section{Time course pattern}

Our results identified methylation patterns at different time points during the course of adipocyte differentiation. At $192 \mathrm{~h}$, a total of 144 DMPs were found (see Supplementary Table S1a for the complete list) in the 6594 differentially expressed genes. Fifty-seven regions (DMRs) showed significant changes in methylation representing $0.8 \%$ of the DEGs at $192 \mathrm{~h}$. (Supplementary Table S2a lists these differentially expressed genes). At $384 \mathrm{~h}$, methylation changed significantly in $11,979 \mathrm{CpG}$

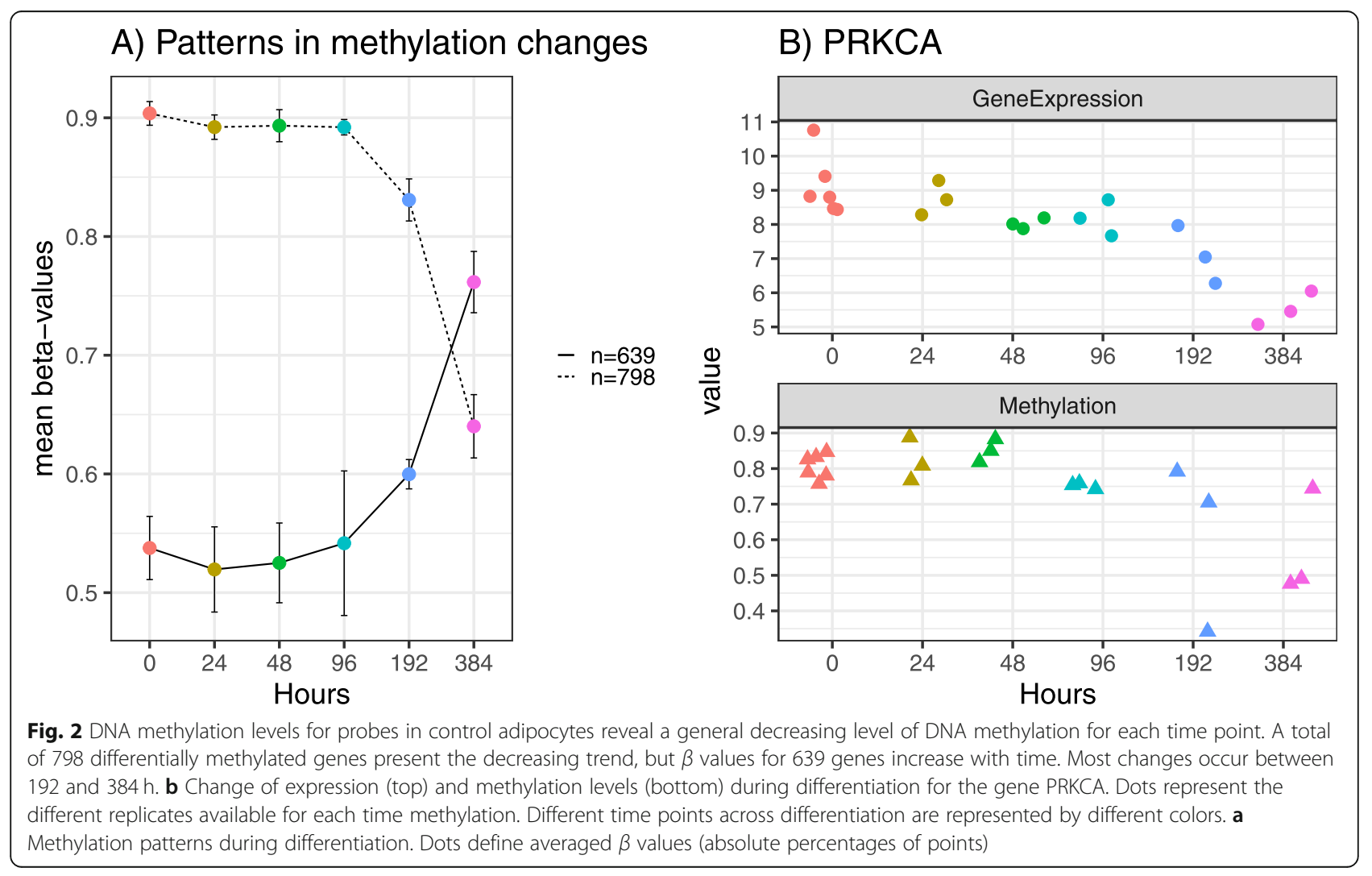


Table 3 Differentially methylated regions can be separated into four groups, depending on their location on the gene at $192 \mathrm{~h}$. Four possible patterns can then be detected, considering gene expression $(\mathrm{G})$ and methylation regulation $(\mathrm{M})$, which can be increasing $(\uparrow)$ or decreasing $(\downarrow)$

\begin{tabular}{llllll}
\hline Location & $\mathbf{M} \downarrow \mathbf{G} \uparrow$ & $\mathbf{M} \uparrow \mathbf{G} \downarrow$ & $\mathbf{M} \uparrow \mathbf{G} \uparrow$ & $\mathbf{M} \downarrow \mathbf{G} \downarrow$ & Total \\
\hline Promoter & 15 & 3 & 6 & 7 & $\mathbf{3 1}$ \\
Exon & 10 & - & 4 & 4 & $\mathbf{1 8}$ \\
Intron & 3 & 1 & 1 & 3 & $\mathbf{8}$ \\
Total & 28 & 4 & 11 & 14 & $\mathbf{5 7}$ \\
\hline
\end{tabular}

positions (DMPs, supplementary Table S1b) and in 1437 regions (DMRs) in 1254 differentially expressed genes (23.95\% of 5247 DEGs; supplementary Table S2b). A total of 130 of those genes were differentially methylated in multiple regions. Notably, 20 of the 57 DMRs at $192 \mathrm{~h}$ maintained their methylation status at $384 \mathrm{~h}$ (Figure S1 in the supplementary material) suggesting that methylation occurred before $192 \mathrm{~h}$ and lasted at least until 384 h. Gene enrichment analysis revealed that the topranked KEGG pathway for that subset of genes was glyoxylate and dicarboxylate metabolism (e.g., SHMT1, GLUL), and GO terms involved in morphogenesis, adhesion, and developmental processes. Twelve (BCOR, EBF3, ETS2, GLI2, ITGA7, NPC1, PDXK, SPON2, GLUL [41], PLEKHG6, SHMT 1[27], TPD52L2 [66]) of the 20 genes have been shown to be involved in adipocyte differentiation or function, and four (GLUL, PLEKHG6, SHMT1, TPD52L2) are also involved in other types of differentiation or development processes (e.g., neurite, intestinal, cardiac, and others; see Table S3 in supplementary material).

Another group of 20 DMRs was differentially methylated/expressed only at $192 \mathrm{~h}$ (Figure S2 in supplementary material) and returned to the baseline level at $384 \mathrm{~h}$ suggesting that these were de-methylated between these time points. These genes are enriched in $\mathrm{GO}$ term for cell morphogenesis involved in differentiation processes (SPINT2, EFNA3, FN1, MBP) (full list of GO terms in supplementary material, Table S4). Among this group of

Table 4 Differentially methylated regions can be separated into four groups, depending on their location on the gene at $384 \mathrm{~h}$. Four possible patterns can then be detected, considering gene expression $(G)$ and methylation regulation $(M)$, which can be increasing $(\uparrow)$ or decreasing $(\downarrow)$

\begin{tabular}{llllll}
\hline Location & $\mathbf{M} \downarrow \mathbf{G} \uparrow$ & $\mathbf{M} \uparrow \mathbf{G} \downarrow$ & $\mathbf{M} \uparrow \mathbf{G} \uparrow$ & $\mathbf{M} \downarrow \mathbf{G} \downarrow$ & Total \\
\hline Promoter & 218 & 368 & 171 & 230 & $\mathbf{9 8 7}$ \\
Exon & 63 & 48 & 16 & 145 & $\mathbf{2 7 2}$ \\
Intron & 40 & 25 & 7 & 87 & $\mathbf{1 5 9}$ \\
Intergenic & 8 & 1 & 3 & 7 & $\mathbf{1 9}$ \\
Total & 329 & 442 & 197 & 469 & $\mathbf{1 4 3 7}$ \\
\hline
\end{tabular}

genes, CTDSP2 [16, 24] and LSS [47] have been individually studied for their roles in neuronal or sex differentiation processes, respectively. The remaining 17 DMRs were differently methylated/expressed at $192 \mathrm{~h}$ but were not significantly expressed or methylated at $384 \mathrm{~h}$.

Genes and pathways identified in this in vitro study play roles in obesity and related conditions. Epigenomewide association has recently shown that BMI was associated with widespread changes in DNA methylation in 210 candidate genes. Twenty-five of those candidate genes [73] were also differentially methylated at $384 \mathrm{~h}$ (full list in supplementary Table S5). Among these DMRs, SREBF1, HOXA5, CPT1A, LPIN1, and PHGDH have established roles in adipose tissue biology and insulin resistance.

\section{Pathway enrichment analysis}

Network activity scores were calculated with NASFinder [51] for all DMRs at $384 \mathrm{~h}$ to investigate how pathways involved in converting a pre-adipocyte to a mature adipocyte may be influenced by methylation changes. This tool identifies statistically significant sub-networks and scores them by connecting a list of differentially expressed genes to key regulators (in this case, TFs). NASFinder analysis revealed 29 significant pathways (the 10 most significant are shown in Table 5, and all the pathways can be found in supplementary Table S6. Pathway visualizations are available on http://www.cosbi.eu/ fx/2930/Visualization_C_TP384_DMR_NASFinder.zip).

The pathway with the highest activity score was phospholipase C D1 in phospholipid-associated cell signaling. Several of the identified pathways are hallmarks of adipogenesis or function in adipocytes (e.g., $R X R$ and $R A R$ heterodimerization, $F X R$ and $L C R$ regulation), but others contribute new information on the differentiation process. Four of the 18 DMRs (in ICAM1, PRKCA, $R A C 1, R A N$ genes) involved in the 29 TF pathways were shown to significantly change also at the protein level. ICAM1 maps to the integrin signaling pathway (Supplement Table S6) and may contribute to priming inflammatory processes if misregulated [43]. PRKCA (Fig. 2b) is involved in 11 of the 29 pathways demonstrating its central role in cell signaling. RAC1 mapped to the semaphoring signaling (Supplement Table S6) and is a key signaling component for translocation of GLUT4 to the cell surface [34]. RAN is in the non-canonical WNT signaling pathway, and this GTPase is also involved in several intracellular transport processes necessary for cell fate determination, death, proliferation, differentiation, and transformation [49]. Statistical results for the 18 DMRs involved in the pathways can be found in Table 6 .

One mechanism by which methylation can influence gene expression is by either positively or negatively altering access of transcription factor (TFs) to their binding 
Table 5 The ten most significant pathways from the NASFinder TFs analysis on the 1437 significant DMRs at $384 \mathrm{~h}$ are displayed. The $p$ value, the Network Activity Score (NAS), the identified TF, and the DMRs involved in each pathway are added

\begin{tabular}{|c|c|c|c|c|}
\hline Pathways & NAS & $p$ value & DMRs in the pathway & TF \\
\hline BioCarta phospholipase C D1 in phospholipid-associated cell signaling & 0.322 & 0.005 & PRKCA & JUNB \\
\hline BioCarta CBL-mediated ligand-induced downregulation of EGF receptors & 0.191 & 0.008 & PRKCA & MET \\
\hline BioCarta activation of PKC through G protein-coupled receptor & 0.186 & 0.003 & PRKCA & NFKBIA \\
\hline BioCarta apoptotic signaling in response to DNA damage & 0.167 & 0.011 & APAF1, BID, PRKCA & TP53 \\
\hline BioCarta role of MEF2D in T cell apoptosis & 0.163 & 0.018 & MEF2D, PRKCA & EP300 \\
\hline BioCarta FXR and LXR regulation of cholesterol metabolism & 0.115 & 0.010 & ABCA1, NR1H3 & RXRA \\
\hline BioCarta cadmium induces DNA synthesis and proliferation in macrophages & 0.088 & 0.013 & PRKCA & MYC \\
\hline BioCarta TPO signaling pathway & 0.064 & 0.029 & PRKCA, STAT5A & STAT3 \\
\hline BioCarta effects of calcineurin in keratinocyte differentiation & 0.060 & 0.022 & PRKCA & SP3 \\
\hline Reactome regulation of gene expression by hypoxia-inducible factor & 0.056 & 0.012 & CITED2 & HIF1A \\
\hline
\end{tabular}

Genes in bold are upregulated

sites [42]. Binding sites of differentially expressed transcription factors in promoters of differentially expressed genes were analyzed by data mining methods. Among the 181 transcription factors identified in the ENCODE database, 61 were found differentially expressed at $192 \mathrm{~h}$ and 56 at $384 \mathrm{~h}$. No consistent or significant binding motifs in the DMRs in promotors at $192 \mathrm{~h}$ were found. However, $24 \mathrm{mo-}$ tifs were enriched in the differently methylated promoters at $384 \mathrm{~h}$. Of those, nine were binding sites for differentially expressed TFs (TFAP2A, ELF1, ETS1, E2F4, E2F1, NR2C2 [59], NR2F2, RXRA, FLI1), which are involved in a large number of intracellular processes such as E2F4's [28] role in suppression of anti-proliferation-associated genes and E2F1-mediated [56] induction of the transcription factor PPARy. The binding site motifs for those TFs were found in a total set of 486 DMRs (see supplementary Table S7).

Table 6 Statistics for the genes identified by the NASFinder as involved in the TF pathways. These genes show significant changes at $384 \mathrm{~h}$ in their methylation level and gene expression. Four of them are differentially expressed also at the proteomic level. Changes between 384 and $\mathrm{O}$ h are displayed for each studied omics, together with the adjusted $p$ value. The region on the gene where the DMR was found is added in the table

\begin{tabular}{|c|c|c|c|c|c|c|c|}
\hline Gene & DMR location & Delta Me & FDR Me & Log FC GE & adj Pval GE & Log FC Pr & adj Pval Pr \\
\hline $\mathrm{ABCA} 1$ & Intron & $-1.17 \mathrm{E}-01$ & $5.39 E-03$ & $1.66 \mathrm{E}+00$ & $1.46 \mathrm{E}-05$ & - & - \\
\hline APAF1 & Promoter & $3.13 \mathrm{E}-02$ & $1.29 \mathrm{E}-03$ & $-3.00 E+00$ & $7.51 \mathrm{E}-11$ & - & - \\
\hline $\mathrm{BID}$ & Promoter & $-3.31 \mathrm{E}-02$ & $4.20 \mathrm{E}-02$ & $-1.91 \mathrm{E}+00$ & 7.89E-07 & - & - \\
\hline CITED2 & Promoter & $1.67 \mathrm{E}-02$ & 1.17E-02 & $-1.14 \mathrm{E}+00$ & $3.89 \mathrm{E}-03$ & - & - \\
\hline ETS2 & Exon & $-5.49 \mathrm{E}-01$ & $1.80 \mathrm{E}-02$ & $-3.29 E+00$ & $1.65 \mathrm{E}-12$ & - & - \\
\hline HMOX1 & Promoter & $-7.67 \mathrm{E}-02$ & $4.73 \mathrm{E}-02$ & $4.44 \mathrm{E}+00$ & $1.23 \mathrm{E}-15$ & - & - \\
\hline HSD17B4 & Promoter & $-1.19 E-01$ & $1.31 \mathrm{E}-02$ & $1.74 \mathrm{E}+00$ & $7.11 \mathrm{E}-06$ & - & - \\
\hline ICAM1 & Promoter & $-4.91 \mathrm{E}-02$ & $3.30 \mathrm{E}-03$ & $-2.43 \mathrm{E}+00$ & 1.19E-08 & $-7.39 \mathrm{E}-01$ & $2.45 \mathrm{E}-05$ \\
\hline MEF2D & Promoter & $2.51 \mathrm{E}-02$ & $1.45 \mathrm{E}-02$ & $-1.62 E+00$ & 1.17E-05 & - & - \\
\hline NCOR2* & Intron & $-1.26 \mathrm{E}-01$ & $5.26 \mathrm{E}-03$ & $-1.31 \mathrm{E}+00$ & $5.45 E-04$ & - & - \\
\hline $\mathrm{NR} 1 \mathrm{H} 3$ & Promoter & $2.05 \mathrm{E}-02$ & $2.27 \mathrm{E}-02$ & $4.83 \mathrm{E}+00$ & $4.54 \mathrm{E}-18$ & - & - \\
\hline PCNA & Promoter & $-6.65 \mathrm{E}-02$ & $4.51 \mathrm{E}-02$ & $-2.70 \mathrm{E}+00$ & $2.02 E-09$ & - & - \\
\hline PRKCA & Promoter & $-7.76 \mathrm{E}-02$ & $4.56 \mathrm{E}-02$ & $-3.34 \mathrm{E}+00$ & $6.50 E-13$ & $-1.26 \mathrm{E}+00$ & 1.97E-06 \\
\hline $\operatorname{RAC} 1^{* \circ}$ & Promoter & $-9.51 \mathrm{E}-02$ & 8.33E-03 & $-3.32 \mathrm{E}+00$ & $1.56 \mathrm{E}-12$ & $-8.47 \mathrm{E}-01$ & $1.40 \mathrm{E}-05$ \\
\hline RAN & Promoter & 2.87E-02 & $1.25 \mathrm{E}-02$ & $-1.77 \mathrm{E}+00$ & 4.33E-06 & $-8.19 E-01$ & $2.36 \mathrm{E}-05$ \\
\hline ROCK1 & Promoter & $-2.05 E-01$ & $3.59 E-02$ & $-1.16 \mathrm{E}+00$ & 5.75E-03 & - & - \\
\hline SREBF1 & Promoter & $-1.41 \mathrm{E}-01$ & $3.96 \mathrm{E}-02$ & $4.62 E+00$ & $2.43 E-15$ & - & - \\
\hline STAT5A & Promoter & $-1.30 \mathrm{E}-01$ & $2.63 \mathrm{E}-02$ & $3.03 E+00$ & $1.56 \mathrm{E}-11$ & - & - \\
\hline
\end{tabular}


Mapping these 486 DMRs to GO terms and pathways is challenging since individual genes are regulated by multiple transcription factors. However, analysis of the pattern of genes (total) methylated (up or down)/ expressed (up or down) at $384 \mathrm{~h}$ (from supplementary Table S2b) indicated that over $50 \%$ of genes mapped to GO or pathways in metabolism categories (at $p<0.1$ ). No cytoskeleton or extracellular matrix genes had the expected down/up pattern (Supplementary Table S8). More specific methylation mapping methods are needed to fully test and explain these putative associations.

\section{Integration of methylation, gene expression, and protein} expression changes in fully differentiated adipocytes

Proteomic data from the Somalogic platform identified and confirmed certain protein levels to the observed DNA methylation events. The results of the integration of methylation, gene expression, and protein abundances are summarized with Venn diagrams in Fig. 3. An overlap among the three omics data was found only at $384 \mathrm{~h}$ (Fig. 3a), while at $192 \mathrm{~h}$ (Fig. 3b), none of the studied genes showed consistent changes at the three different levels. A total of 73 proteins from the SomaLogic SOMAscan V1.0 panel (total of 1129 proteins) showed a significant change in the amounts between baseline and $384 \mathrm{~h}$ consistent with promoter, intron, and exon methylation status. Nine of these 73 proteins overlap with multiple DMRs on DEGs, resulting in a total of 84 genomic regions with proteomic, transcriptomic, and methylation changes. Eight of the 84 DMRs were upregulated at the proteomic level, while 76 are downregulated (Supplementary Table S9). Sixty-three of these were consistent with the typical pattern of methylation upregulation and downregulation of gene expression. Thirteen of the DMRs overlapping with downregulated proteins and 8 DMRs on upregulated proteins were found to have upregulated methylation and upregulation of gene expression. DNA methylation in the promoter regions typically silences genes while methylation within introns and exons is reported to positively correlate to gene expression [77]. Analysis of the pathways of the 73 proteins overlapping with DMRs will be biased since the SOMAscan version 1.0 platform is based primarily on secreted and membrane proteins $(\sim 66 \%)$ found in the blood with a subset derived from cellular contents $(\sim$ $33 \%)$.

\section{Influence of fructose on DNA methylation}

The status of DNA methylation sites in SGBS adipocytes exposed to different concentrations of fructose $(2.5,5$, and $10 \mathrm{mM}$ ) for 192 and $384 \mathrm{~h}$ was also assessed from the induction of differentiation (Table 7). At each fructose concentration, the methylation status of the same genes was compared to the control (without fructose at the same time point) at 192 and $384 \mathrm{~h}$. Similar to the control case presented above, we performed an integration of methylation and transcriptomics. However, at $192 \mathrm{~h}$, this analysis identified only 6 DMPs in the presence of $10 \mathrm{mM}$ fructose (Supplementary Table S10a) and no DMRs. At $384 \mathrm{~h}, 139$ and 27 DMPs were

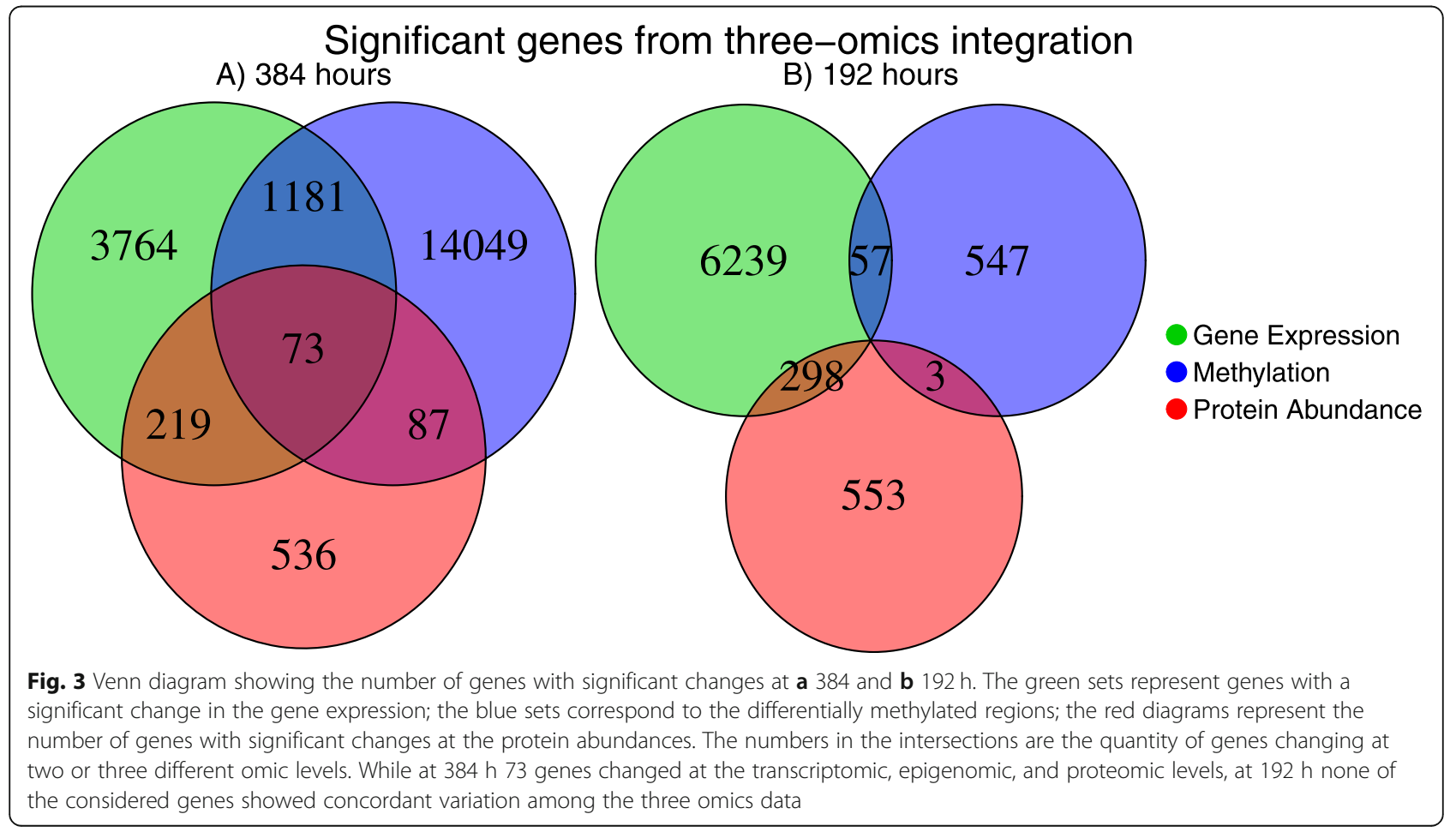


Table 7 Genome-wide differentially methylated regions (DMRs) found at different concentrations of fructose at 192 and $384 \mathrm{~h}$

\begin{tabular}{lll}
\hline Fructose $(\mathbf{m M})$ & Time point $(\mathbf{h})$ & Genome-wide DMRs \\
\hline 2.5 vs 0 & 192 & - \\
& 384 & 26 \\
5 vs 0 & 192 & - \\
& 384 & 7 \\
10 vs 0 & 192 & 3 \\
& 384 & - \\
\hline
\end{tabular}

significant in response to $2.5 \mathrm{mM}$ and $5 \mathrm{mM}$ fructose, respectively (Supplementary Table S10b and S10c). Only 3 DMRs (EDEM1, RNF145, and SLC3A2) in genes differentially expressed were identified for $2.5 \mathrm{mM}$ fructose, none for $5 \mathrm{mM}$ fructose.

Since so few DMRs were found in genes differentially expressed at 192 and $384 \mathrm{~h}$ in response to varying fructose concentrations, genome-wide analysis of DMRs was performed to find the general effect of fructose on methylation. At $192 \mathrm{~h}$, three significant genome-wide DMRs (Supplementary Table S11a) were found only for the highest dose of fructose $(10 \mathrm{mM})$. At $384 \mathrm{~h}$ (Table 7), 26 genome-wide DMRs were detected with $2.5 \mathrm{mM}$ of fructose (Fig. 4 and Supplementary Table S11b), and 7 genome-wide DMRs were detected with $5 \mathrm{mM}$ of fructose (Supplementary Table S11c). Most of the DMRs identified at $2.5 \mathrm{mM}$ fructose at $384 \mathrm{~h}$ occurred in the promoter regions of the genes (22 of the 26 DMRs). The addition of fructose resulted in the up-methylation of the majority of these gene promoters (18 of the 22 DMRs) (Table 8). Functional analysis of these 26 significant DMRs resulted in 9 enriched pathways, for example, branched-chain amino acid metabolic process and oxoacid metabolic process (Table 9).

\section{Linked transcripts and proteins but not DMRs}

Some genes (219) showed corresponding abundance changes at the protein and transcript level but not at the methylation level (Supplementary Table S12) at 384 h. DMRs at these sites were likely maintained at time points which were not analyzed in this study. Subsets of these genes mapped to 312 pathways (Benjamini adjusted $p$ value $<0.05)$ with the secretory, membrane, and extracellular processes featuring as the most significant (< 10E-25) (see Supplementary Table S13). The GO terms may indicate a bias towards secretory proteins that constitute the SOMAscan assay panel.

\section{Validation with replication study}

The RNA and DNA used for the transcriptomic and methylation analysis were obtained from cells plated on

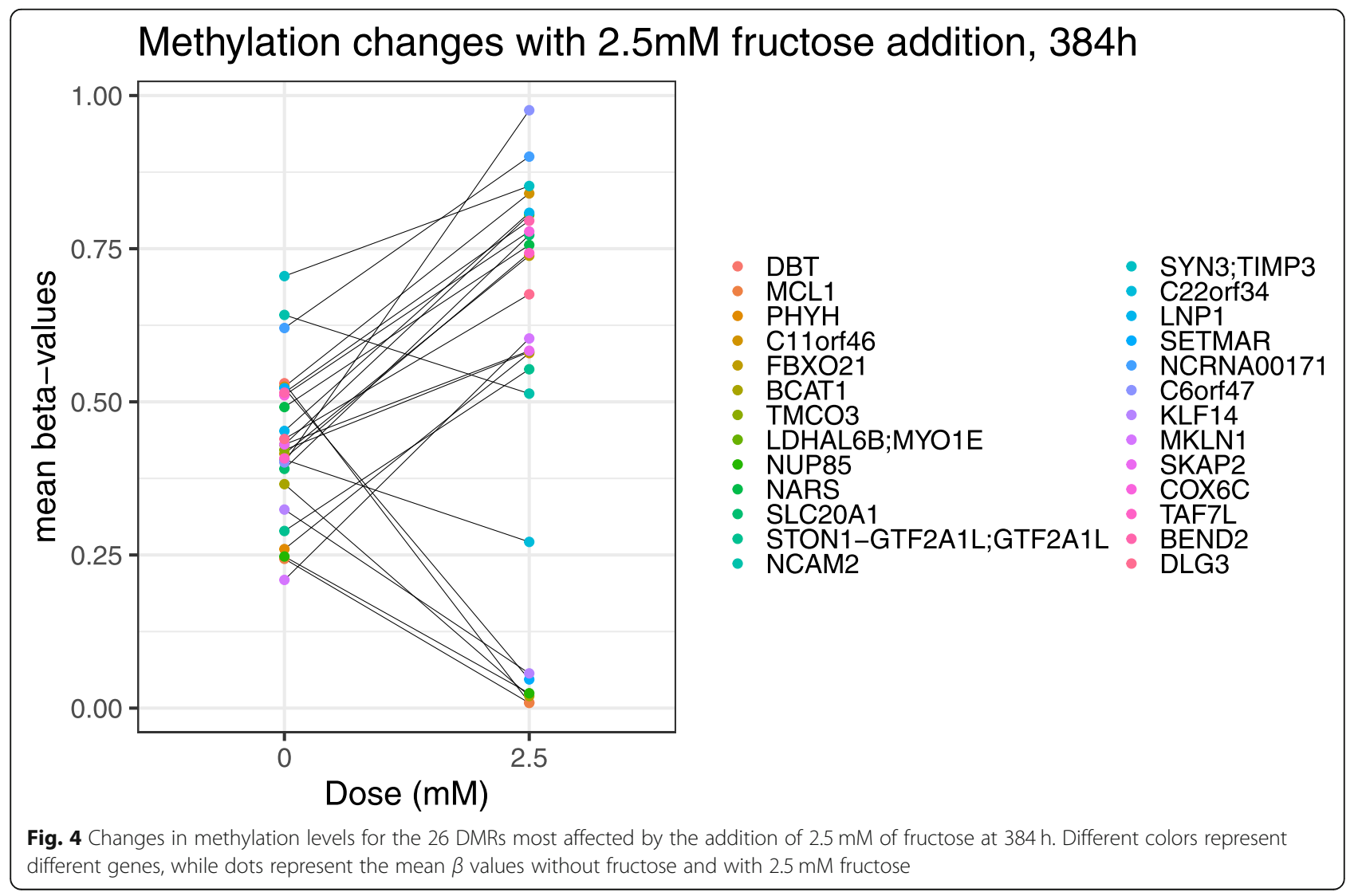


Table 8 Location on the genes and regulation of the 26 DMRs found at $384 \mathrm{~h}$ for $2.5 \mathrm{mM}$ fructose addition

\begin{tabular}{llll}
\hline Location & $\mathbf{M} \downarrow$ & $\mathbf{M} \uparrow$ & Total \\
\hline Promoter & 7 & 15 & 22 \\
Exon & 0 & 1 & 1 \\
Intron & 1 & 2 & 3 \\
Total & $\mathbf{8}$ & $\mathbf{1 8}$ & $\mathbf{2 6}$ \\
\hline
\end{tabular}

different plates cultured at the same time and under identical conditions. The transcriptomic and methylation analyses were generated in the same genomics facility. Since we also had access to the gene expression dataset obtained from an experiment conducted at different hours but under similar experimental conditions [51], we analyzed the integration of methylation data reported here with the gene expression dataset reported in the previous study [51]. The dataset was generated with 8 Illumina Human HT-12 version 4 BeadChips (Ilumina, Inc., San Diego, CA) hybridized with the RNA from 18 cell cultures at different time points $(0,6,48,96,192,384 \mathrm{~h})$.

The secondary analysis conducted on this gene expression dataset led to similar but less significant results (Table 10). For example, significant DMRs on DEGs were found only at $384 \mathrm{~h}$ for a total of 198 genes over the 8279 DEGs found in the previously published study. Sixty-eight of these genes (complete list in Supplementary Table S14) were found to be differentially methylated when using data from the same experiment. Additionally, 7 of the 198 genes showed changes also at the proteomic level: three of them (THBS2, CRLF1, and C3) were found also in the analysis with the transcriptomic data used for our study.

Only a few DMRs with corresponding DEGs were identified in cells exposed to fructose in this second dataset: 17 DMRs for $2.5 \mathrm{mM}$ fructose and 3 for $5 \mathrm{mM}$ addition at $384 \mathrm{~h}$. These results are in agreement with that obtained for data from the same experiment, with DMRs only at $384 \mathrm{~h}$ and diminishing with fructose addition.
The two gene expression datasets were generated by separate laboratories using the same methodologies, which may explain the differences in the results [11].

\section{Discussion}

Genome-wide changes in DNA methylation of preadipocytes cells induced to differentiate into mature adipocytes were analyzed to determine the role of DNA methylation in regulating gene and subsequently protein expression in control ( $5 \mathrm{mM}$ glucose) cells. The effect of varying concentrations of fructose on methylation status and transcriptional regulation was also analyzed since fructose stimulates anabolic processes of glutamate and de novo fatty acid synthesis [70] and alters glucose metabolism to induce more energy [69].

\section{DMRs in control conditions}

A previous report [67] concluded that DNA methylation of 84 genes was relatively stable between 0 and $240 \mathrm{~h}$ during human mesenchymal stem cell adipogenesis and that changes in DNA methylation were not an underlying mechanism regulating the gene expression during adipocyte differentiation. Our results largely confirm these findings since DNA methylation did not change appreciably at 24,48 , and $96 \mathrm{~h}$ and less than $1 \%$ at $192 \mathrm{~h}$. The majority of methylation regions at $192 \mathrm{~h}$ were conserved at $384 \mathrm{~h}$. The subset of genes with transient methylation (methylated at 192 but not at 384) occurred in genes associated to cell morphogenesis involved in the differentiation process (SPINT2, EFNA3, FN1, MBP). In addition, significant changes in methylation linked to changes in the gene expression occurred in almost 25\% (1254 of 5237) of the sites analyzed at $384 \mathrm{~h}$ compared to pre-induction. These results are consistent with our previous metabolic [70] and transcriptomic analyses [51] that showed adipocyte-specific metabolism, and gene regulation at $192 \mathrm{~h}$ of differentiation becomes more "robust" by $384 \mathrm{~h}$ when adipocytes are in the fully differentiated state. That is, a complex set of interactions

Table 9 Enriched pathways from the DAVID analysis on the 26 DMRs found to be significant for 2.5 mM of fructose addition at 384 $h$. The $p$ value and the genes involved in the pathways are shown in the table

\begin{tabular}{llll}
\hline Category & Term & $\boldsymbol{p}$ value & Genes \\
\hline REACTOME_PATHWAY & R-HSA-70895: Branched-chain amino acid catabolism & 0.023 & BCAT1, DBT \\
GOTERM_BP_FAT & GO:0006367 transcription initiation from RNA polymerase Il promoter & 0.024 & STON1-GTF2A1L, GTF2A1L, TAF7L \\
GOTERM_BP_FAT & GO:0019752 carboxylic acid metabolic process & 0.025 & BCAT1, DBT, NARS, LDHAL6B, PHYH \\
GOTERM_BP_FAT & GO:0043436 oxoacid metabolic process & 0.026 & BCAT, DBT, NARS, LDHAL6B, PHYH \\
GOTERM_BP_FAT & GO:0009083 branched-chain amino acid catabolic process & 0.026 & BCAT1, DBT \\
GOTERM_BP_FAT & GO:0009081 branched-chain amino acid metabolic process & 0.030 & BCAT1, DBT \\
GOTERM_BP_FAT & GO:0006082 organic acid metabolic process & 0.035 & BCAT, DBT, NARS, LDHAL6B, PHYH \\
GOTERM_BP_FAT & GO:0016054 organic acid catabolic process & 0.037 & BCAT1, DBT, PHYH \\
GOTERM_BP_FAT & GO:0006352 DNA-templated transcription initiation & 0.039 & STON1-GTF2A1, GTF2A1L, TAF7L \\
\hline
\end{tabular}


Table 10 Differentially methylated positions (DMPs), differentially methylated regions (DMRs), and differentially expressed genes (DEGs) for the validation dataset. The results obtained at different time points and for different fructose doses are displayed

\begin{tabular}{lllll}
\hline Time point $(\mathbf{h})$ & Fructose doses $(\mathbf{m M})$ & \# DEGs & \# DMPs on DEGs & \# DMRs on DEGs \\
\hline 6 & 0 & 1005 & - & - \\
48 & 0 & 5574 & 2 & - \\
96 & 0 & 7334 & 4 & 2 \\
192 & 0 & 7248 & 452 & 198 \\
384 & 0 & 8279 & - & - \\
192 & 2.5 vs 0 & 214 & 49 & - \\
384 & 2.5 vs 0 & 2532 & - & - \\
192 & 5 vs 0 & 79 & 6 & 3 \\
384 & 5 vs 0 & 2466 & - & - \\
192 & 10 vs 0 & 64 & 1 & - \\
384 & 10 vs 0 & 2338 & \\
\hline
\end{tabular}

between metabolic pathways, transcriptional regulation, and DNA methylation that cause the final maturation of the adipocyte and/or DNA methylation ensures that the cell remains in its fully differentiated state (that is, it is not causal for differentiation, but rather a postdifferentiation mechanism to prevent de-differentiation).

Changes in DNA methylation occurred in genes and pathways known to be involved in adipogenesis (e.g., a PPARG receptor linked to $R A R$ and $R X R$, visualization on http://www.cosbi.eu/fx/2930/Visualization_C_TP384_ DMR_NASFinder.zip) as well as pathways not previously associated with adipogenesis (supplement Table S4 and visualization on http://www.cosbi.eu/fx/2930/Visualization C_TP384_DMR_NASFinder.zip). Upregulated genes at 384 $\mathrm{h}$ mapped to lipid metabolism, mitochondria, oxidoreductase, and other pathways regardless of the state of methylation. Downregulated genes mapped to cell adhesion, cell cycle, cell division, and cytoskeleton (among others) pathways and also were independent of methylation status. These results suggest that methylation is a consequence and not a driver of the final maturation stage of adipogenesis.

\section{Integration of DNA methylation, gene expression, and proteomics}

A novel feature of this study was the analysis of DNA methylation, mRNA levels, and selected proteins at 384 $h$ after differentiation. Seventy-three of the DMRs (out of the 84 proteins identified with Somalogic technology with the corresponding DMRs in this dataset) showed significant variation in levels indicating that DNA methylation changes were transmitted to protein levels. Of the 63 downregulated proteins and genes, DNA methylation of the majority of genes occurred in the promoter region. Methylation was also present at more than one region in some genes, for example, upmethylation of COL18A1 occurred both in the intronic and exonic regions of the gene. Alternatively, methylation of some genes (e.g., MRC2, CRLF1, RAC1) occurred in the promoter or either the intronic or exonic regions. DKK [23] and other genes that have well-established roles in adipogenesis have been shown to have methylation consistent with the direction of the expression [68]. More than half of the 73 methylated genes have been identified as such in adipose tissue samples from obese and/or diabetic patients [52]. Many of these genes have not been fully characterized in adipose tissue, and a functional role in the adipogenic process remains to be defined (e.g., CRLF1) [82]. Methylation of several genes and their protein changes are reported here for the first time, and no literature exists describing their expression in adipose tissue (e.g., RPS7, COLEC12) or role in adipogenesis. The integration of gene methylation and their mRNA and protein levels make these likely targets and biomarkers of adipocyte differentiation and contribute to improving our understanding of this process.

\section{Fructose effect on methylation}

Fructose has been implicated in the obesity epidemic and specifically in altering the physiology of adipocytes. Although studying the effects of nutrients in cell culture experiments is controversial because concentrations have to be estimated, the doses used in this in vitro experiment were modeled on circulating levels following fructose ingestion in humans $[46,72]$ and considered that local concentrations (e.g., adipose tissue associated with the intestinal tract) could be higher than reported plasma levels.

An inverse correlation was found between the number of DMRs assayed and fructose levels (Table 6). At $384 \mathrm{~h}$, 26 genome-wide DMRs were detected in cells grown in $2.5 \mathrm{mM}$ of fructose in the presence of $5 \mathrm{mM}$ glucose. Pathway analysis mapped these genes to transcription factor processes and branched-chain amino acid (BCAA) 
catabolism at uncorrected $p$ values of $<0.05$. BCAA catabolism has a functional role in adipocyte differentiation [22], and decreased catabolism of BCAA may be related to insulin resistance, impairment of subcutaneous adipocyte hypertrophy, and associated pathologies [55, 75]. Higher circulating BCAA levels were observed in obese and diabetic patients [55].

Only 7 and 3 DMRs were found when adipocytes were exposed to $5 \mathrm{mM}$ and $10 \mathrm{mM}$ fructose, respectively, at $384 \mathrm{~h}$ post-induction of differentiation. These small numbers of genes precluded pathway analysis, but no apparent pattern was observed. Individual genes can be annotated and associated with whole body phenotypes. For example, the endoplasmic reticulum degradationenhancing alphamannosidase-like protein1 (EDEM1) found to be differently methylated at $10 \mathrm{mM}$ fructose is an endoplasmic reticulum stress (ERS) marker [58]. Acute ERS can weaken the capacity of mature adipocytes to store lipids, and chronic ERS can impair the adipogenic potential of preadipocytes [35]. Disruption of these pathways could contribute to obesity-associated morbidities such as lipid spillover, ectopic fat deposition, and ultimately insulin resistance [10]. Epigenetic modifications in ring finger protein 145 (RNF145, a metal binding proteins), also found at $10 \mathrm{mM}$ fructose, were associated with BMI, waist circumference, and changes in BMI in African American adults [13].

Fructose has moderate effects on methylation at $384 \mathrm{~h}$ at a concentration of $2.5 \mathrm{mM}$, a 1:2 ratio with the $5 \mathrm{mM}$ glucose in the culture media. However, changes in methylation decreased at equimolar doses $(5 \mathrm{mM}$ fructose added to basal $5 \mathrm{mM}$ glucose) or 2:1 (10 mM fructose with $5 \mathrm{mM}$ basal glucose). We speculate that fructose may play a signaling/regulatory role at doses less than 1:1 fructose to glucose, but at equimolar or greater levels, fructose participates as a substrate and is "shunted" to the metabolic pathways to produce stored (oleate) and released fatty acids (palmitate) as demonstrated in our previous work [70].

\section{Limitations}

Comparing gene expression datasets generated by different laboratories is known to be problematic [11]. In this study, we compared and integrated two sets of gene expression datasets with the methylation data, of which, one of the gene expression datasets was previously published by our team while the second gene expression dataset was generated from cells cultured simultaneously with cells that were used for the methylation data. Our observation was similar to previous reports [11] in that although the trends were similar between the two separate gene expression datasets generated in different laboratories, differences were also found.
Another limitation of this study was the use of a proteomic assay technology (i.e., SomaLogic platform) that is based on a subset of proteins that are typically found in the blood. Nevertheless, these diverse high-throughput methods allow for identifying and linking changes at the chromosome level through protein levels. The integration of these diverse data types was possible by the use of a highly characterized euploid cell line $[2,19]$ as to more complex adipose tissue which would have multiple cell types.

\section{Cell model}

The cell line (SGBS) used in these experiments was derived from a male child with Simpson-Golabi-Behmel syndrome (OMIM \# 312870), an overgrowth syndrome with multiple clinical features such as facial and cardiac abnormalities, macrocephaly, and organomegaly. SGBS is associated with genomic rearrangement and mutations in glypican-3, a heparan sulfate proteoglycan [65]. The cell line has retained its diploid character in culture. While cells in culture lack communication between different cells in the tissue and physiological factors from other organs that occur in vivo, SGBS cells have been used extensively as a human model for pre-adipocyte differentiation to mature adipocytes [2, 19]. Our previous study of global changes in networks and pathways during adipogenesis in SGBS corroborated the results from many studies in mouse 3T3-L1 that analyzed individual pathways or subsystems [50]. A direct comparison between SGBS and primary human white subcutaneous adipocytes from 4 obese individuals indicated quantitative but not qualitative differences in the expression of extracellular matrix proteins, some metabolic pathways, and mitochondrial respiration [81]. The differentiation process was similar between SGBS and primary adipocytes, and these direct comparisons can be informative for understanding adipogenesis in vivo.

\section{Conclusions}

The transcriptomic and methylation data obtained in this study indicated that a majority of DNA methylation and resultant gene expression patterns are "pre-programmed" since up- or downregulation of gene expression does not appear to be causatively coupled to a promoter, exon, or intron methylation. However, promoter methylation of a subset of genes may be causatively linked to expression. In addition, the differentiation program apparently overrides the differences in the type and level of nutrients (fructose vs glucose) consistent with our previous studies of the metabolic fate of fructose [70] and the effect of fructose on glucose metabolism [69] in these cells. Further research on how nutrients affect methylation, gene expression, protein levels, and the differentiation program should focus on mesenchymal stem cells to preadipocyte transition. 


\section{Methods}

\section{Fructose treatment of SGBS cells}

Human Simpson-Golabi-Behmel syndrome (SGBS) preadipocytes, kindly provided by Martin Wabitsch, were used and cultured as described in a previous study [70]. Briefly, the SGBS preadipocytes cells were maintained at $37{ }^{\circ} \mathrm{C}$ in a humidified incubator flushed with $5 \% \mathrm{CO}_{2}$. The growth medium consisted of DMEM:F12 (1:1), $33 \mathrm{mM}$ biotin, and $17 \mathrm{mM}$ pantothenate containing $10 \%$ fetal bovine serum and $1 \%$ penicillin-streptomycin. One day post-confluence, the cells were initiated to differentiate into adipocytes by the addition of a serum-free differentiation medium containing DMEM with $25 \mathrm{nM}$ dexamethasone, $500 \mu \mathrm{M}$ IBMX, $2 \mu \mathrm{M}$ rosiglitazone, $0.01 \mathrm{mg} / \mathrm{ml}$ human transferrin, $2 \times 10-8 \mathrm{M}$ insulin, 10-7 M cortisol, $0.2 \mathrm{nM}$ T3, $33 \mathrm{mM}$ biotin, and $17 \mathrm{mM}$ pantothenate. Following 4 days of maintenance in serum-free differentiation medium, the medium was changed to a serum-free adipogenic medium consisting of DMEM:F12 (1:1) with $0.01 \mathrm{mg} / \mathrm{ml}$ human transferrin, $2 \times 10-8 \mathrm{M}$ insulin, 10-7 M cortisol, 0.2 nM T3, $33 \mathrm{mM}$ biotin, and $17 \mathrm{mM}$ pantothenate. Adipogenic medium is essentially similar to the differentiation medium but lacks IBMX, dexamethasone, and rosiglitazone. The medium was changed every 2 days from the initiation of differentiation. The SGBS cells differentiate into adipocytes by day 14 of differentiation as by Oil Red O staining, seen previously during the establishment of the differentiation methods of the cells, in the lab.

\section{Fructose treatment of SGBS cells}

SGBS preadipocytes were plated at $2 \times 10^{5}$ cells in 100 $\mathrm{mm}$ dishes, supplemented with $10 \mathrm{ml}$ growth medium, grown to confluence, and initiated to differentiate as per Varma et al. [70]. All media used for the growth, differentiation, and maintenance of adipocytes contained a basal amount of $5 \mathrm{mM}$ glucose, equivalent to the normal blood glucose concentration. Cells for RNA and DNA isolations were collected at different time points across differentiation at $24,48,96,192$, and $384 \mathrm{~h}$. In order to determine the effects of fructose exposure on adipocytes at concentrations reported in the systemic circulation, in response to fructose-rich food [29], different doses of fructose including 2.5, 5, and $10 \mathrm{mM}$ fructose were added to the media at the initiation of differentiation and maintained in the medium until the collection of cells and medium at the end points of either $192 \mathrm{~h}$ or until day $384 \mathrm{~h}$ of differentiation. The medium was changed every 2 days, from the initiation of differentiation to the collection of cell lysate experimental assays. Cell lysates from the control or fructose-treated adipocytes were collected for DNA and RNA isolations. For RNA, the media were completely aspirated from cells, and a total of $700 \mu \mathrm{l}$ of QIAzol lysis reagent (Qiagen, Cat No./ID: 79306) was added to the cells, and the lysed cells were scraped and collected in an Eppendorf vial and sheer disrupted by passing through a tuberculin syringe about 6 times and the lysates are flash frozen. For obtaining samples for DNA isolation, the media were removed and cells were washed with PBS and aspirated to remove all PBS. The cells were gently scraped in the presence of a total of $400 \mu \mathrm{l}$ of PBS that was added to the plates and collected using a pipette fitted with a wide mouth tip and transferred to an Eppendorf vial and flash frozen. All experiments across all our studies were conducted at the same passage numbers, and culture condition differentiations were adhered to rigorously.

\section{Study design}

The study design is summarized in Table 1 . The study was thus designed such that different concentrations of fructose were added to a medium containing $5 \mathrm{mM}$ glucose to mimic the effects of different concentrations of fructose in circulation. We included a broad range of fructose concentrations $(0.1-10 \mathrm{mM})$ to examine the impact of the reported concentrations of fructose in adipocytes $[29,46]$. Triplicate plates of cells in culture were harvested for DNA methylation or separately for transcriptomics assays at specific time points including $24,48,96,192$, and $384 \mathrm{~h}$ for control adipocytes (six replicates were harvested at $0 \mathrm{~h}$ ). Cultures treated with different concentrations of fructose $(2.5,5$, and $10 \mathrm{mM})$ were harvested at 192 and $384 \mathrm{~h}$ following the initiation of differentiation (Table 1). For proteomic SOMAscan assays (version 1 [1149 somamers], Somalogic, Boulder, CO), cell lysates were obtained from cultures differentiated for $0,96,192$, and $384 \mathrm{~h}$ following the induction of differentiation in a control medium supplemented with $0,2.5,5$, and $10 \mathrm{mM}$ fructose.

\section{DNA methylation \\ Platform}

Genome-wide methylation was assessed using the Illumina Infinium HumanMethylation450K array platform (Illumina, San Diego, CA, USA) that contains a total of 485,512 CpG sites. Samples were randomly distributed over four different BeadChips to reduce batch effects. CpG sites were then annotated with the $R$ package ilmn12.hg.19 [26] (v 0.6.0), which identified the genes and the regions on the genome. Illumina GenomeStudio software was used to extract the raw signal intensities.

\section{Normalization}

Preprocessing was performed with the function preprocessIllumina from the $\mathrm{R}$ package Minfi [4] 1.22.1. This method was applied to reduce Infinium I/II type bias and correct for background. Absolute percentages of methylation ( $\beta$ values) were then extracted and normalized with the SWAN method [40]. For each CpG site, 
averaged $\beta$ values across the cell replicates were considered for the following analysis.

\section{Differentially methylated positions}

The Minfi package was used to detect differentially methylated positions. Statistical significance of $\mathrm{CpG}$ sites was assessed with a moderated $F$-statistic implemented in the function $d m p$ Finder, which uses statistical significance cutoffs to select differentially methylated positions. Since DMPs were used as a starting point for further analysis, an FDR adjusted $p$ value threshold of 0.1 was chosen.

\section{Differentially methylated regions}

In addition to DMPs, differentially methylated regions were identified with the R package COHCAP [74] (version 1.20.0). COHCAP functions use a list of annotated DMPs to compute the average signals from one or more $\mathrm{CpG}$ sites that were found in the same genomic region. A $t$ test with an FDR threshold of 0.05 was applied to find those regions (DMRs) showing a significant difference in the average methylation level. The minimum number of sites needed to create a region was set at 1 , while the change in methylation used to define the DMRs was left as the default values of COHCAP, which is 0.2 . The possibility to use a list of annotated DMPs makes this method suitable for detecting DMRs on specific genes and thus to perform a step of integration analysis. Moreover, COHCAP uses predefined regions, allowing a more controlled analysis, in contrast to methods that define regions [57].

\section{Transcriptomic data}

For RNA isolation, media was completely aspirated from cells and a total of $700 \mu \mathrm{l}$ of QIAzol lysis reagent was added to the cells, and the lysed cells were scraped, collected in an Eppendorf vial, sheer disrupted by passing through a tuberculin syringe about 6 time, and the lysates flash frozen. Cells from replicate wells were used for both RNA and DNA isolation respectively.

\section{Platform}

The dataset was generated with 4 Illumina Human HT12 v-4 BeadChips (Ilumina, Inc., San Diego, CA) hybridized with the RNA from 46 cell cultures at different time points $(0,24,48,96,192,384 \mathrm{~h})$ and for different fructose concentration $(0,2.5 \mathrm{mM}, 5 \mathrm{mM}, 10 \mathrm{mM})$. RNA labeling and microarray hybridization were performed according to the manufacturer's recommendations. Samples for RNA and DNA platform were measured on cells plated at the same time and treated similarly.

\section{Normalization and filtering}

The scanned data was acquired in $\mathrm{R}$ using the package illiminaio [61] (v 0.18.0). The non-normalized summarized bead-level data was then annotated with the $\mathrm{R}$ package illuminaHumanv4.db [18]. Other labeling and analysis methods were performed with the preprocessing pipeline previously described [51].

\section{Differentially expressed genes}

Differential expression analysis was carried out using the limma [62] $\mathrm{R}$ package (version 3.32.5). The probes were ranked by their log-odds scores given by empirical Bayesian moderation of sample variances with an FDR threshold of 0.01 . The DEGs of fully differentiated adipocytes at $384 \mathrm{~h}$ in controls were further processed to identify clusters of co-expressed genes. The clusters were decomposed according to the functional categories of their genes related to the biological functions and pathways (DEG modules). The details of the procedures are described in the paper by Nassiri et al. [51].

\section{Proteomic data}

\section{Proteomic studies}

SGBS preadipocytes were plated at $1 \times 10^{5}$ cells/well in a 6well plate and allowed to reach near confluence before adding a differentiation medium. Samples were harvested from three replicate wells at 4 different time points including day 0 just before the induction of differentiation and then days 4,8 , and 16 after the induction of differentiation.

The spent culture medium (supernatant) from the respective wells was pipetted into an Eppendorf vial, centrifuged at 13,000 RPM for $10 \mathrm{~min}$ at $4{ }^{\circ} \mathrm{C}$ to pellet the cell debris. The supernatant was transferred to a fresh vial and stored at $-80{ }^{\circ} \mathrm{C}$ until used. Cells were washed three times with ice-cold PBS and then lysed by the addition of $125 \mu \mathrm{l}$ Mammalian Protein Extraction Reagent M-PER ${ }^{\circ}$ (Pierce Biotechnology cat \# 78503) supplemented with Halt ${ }^{\text {tix }}$ protease inhibitors (with EDTA) (Pierce biotechnology cat \# 87786 ) at $1 \times$ concentration and incubated for $5 \mathrm{~min}$. Cell lysates were scraped and transferred to a microcentrifuge tube, centrifuged at $13,000 \mathrm{RPM}$ for $10 \mathrm{~min}$ at $4{ }^{\circ} \mathrm{C}$ to pellet the cell debris. The clarified supernatant (lysate) obtained was transferred to a fresh tube and stored at $-80{ }^{\circ} \mathrm{C}$. Protein concentrations in the supernatant and cell lysates were estimated using the Micro BCA Kit (Pierce Biotechnology cat \# 23235) as per the recommended protocol.

\section{Platform}

Cell lysates in replicates were analyzed with the SOMAscan platform (SomaLogic, Inc., Boulder, CO) consisting of 1149 aptamers at different time points $(0,96,192$, and $384 \mathrm{~h})$ and for different doses of fructose $(0,2.5,5$, and $10 \mathrm{mM}$ ). SomaLogic Inc. (Boulder, CO) performed all the proteomic assessments, and samples were analyzed as previously described $[6,20,21,54]$. 


\section{Differentially expressed proteins}

Differentially expressed proteins were found with a robust linear model from the $\mathrm{R}$ package limma [62]. A threshold of 0.05 on moderated empirical Bayesian FDR was set to select significant proteins.

\section{Transcription factors binding sites analysis}

Binding sites of transcription factors (TFs) in DMRs were identified with the function get.enriched.motif of the $\mathrm{R}$ package $E L M E R[78,80]$ 1.6.0. The binding sites were searched on 181 transcription factors identified in the ENCODE database (http://amp.pharm.mssm.edu/ Harmonizome/dataset/ENCODE+Transcription+Factor+ Targets). The CpG sites of all DMPs were used as a background. Motifs occurring at least 10 times and with an odds ratio higher than 1 in the 95\% CI were considered significant. Significant motifs from the same family were summarized with the function motif.relevant.TFs data from the ELMER.data package [79] (v 1.6.0).

\section{Pathway analysis}

Pathways analysis was performed with NASFinder [51]. NASFinder identifies and scores statistically significant subnetworks of an interactome network connecting functionally related genes to its main regulator (e.g., receptors or transcription factors). The analysis described here was adiposespecific using transcription factors as regulators and transcripts that mapped to differentially methylated genes to find the most active pathways influenced by methylation. The $p$ value threshold used to select significant pathways was < 0.05 . Functional pathway enrichment analysis was also performed with DAVID [14], using default parameters and a $p$ value threshold $<0.05$ to analyze the fructose data.

\section{Integration of methylation, gene expression, and protein expression}

The schema representing the different steps of the integration analysis is presented in Fig. 1.

Differentially methylated regions (DMRs), differentially expressed genes (DEGs), and significantly expressed proteins were explored at each time point and each different fructose concentration.

An integrative analysis was then performed by determining the differentially methylated regions (DMRs) that were associated with differentially expressed genes for each of the considered analysis. The location of the DMRs in the gene (promoter, exon, intron, or intergenic) was annotated with the genomation 1.8.0 R package [1]. Integration with protein expression was performed by determining the methylated/expressed genes that were also associated with significantly expressed proteins. All the analyses described here were performed with $\mathrm{R}$ version 3.4.1.

\section{Supplementary Information}

The online version contains supplementary material available at https://doi. org/10.1186/s12263-020-00680-2.

Additional file 1: Figure S1. Methylation patterns during differentiation for the 20 genes showing significant methylation changes both at 192 and 384 hours. To better inspect the patterns, genes are separated in four panels. Dots define averaged $\beta$-values for each time-point, while different colors represent different genes. Figure S2. Methylation patterns during differentiation for the 20 genes significantly methylated/expressed at 192 hours (but not at 384 hours) which methylation levels return to the baseline at 384 hours. For each panel, mean $\beta$-values at each time point are represented by dots. Different colors represent different genes. Figure S3. Distribution of the average beta-values for the DMRs on DEGs at 384 hours. $\beta$-values of DMRs that show anti-correlated changes in methylation and gene expression are depicted in pink. The blue curve describes instead the distribution of $\beta$-values for DMRs showing the same direction of regulation in methylation and gene expression levels.

Additional file 2. Supplementary tables.

\section{Acknowledgements}

This study was supported by the National Center for Toxicological Research (Protocol E0740401 to W), the Food and Drug Administration, and the Nestlé Institute of Health Sciences (Now Nestle Research). The authors would like to thank Dr. Stu Field, SomaLogic Inc., for the initial bioinformatic analysis and discussions on the SOMAscan proteomic assay data. The authors also wish to thank Drs. Leihong Wu and Sangeeta Khare for reviewing the manuscript and providing critical comments and suggestions. SomaLogic ${ }^{\circledast}$ and SOMAscan ${ }^{\circledast}$ are registered trademarks of SomaLogic, Inc.

\section{Disclaimer}

The results and conclusions presented in this paper are solely the opinions of the authors and do not necessarily reflect the opinion of the Food and Drug Administration.

\section{Authors' contributions}

W designed the SGBS cell culture experiments. GTN and W performed the cell culture work. PD, GL, and SM planned and performed the DNA methylation and transcriptomic assays. GT and MPS-B performed the independent DNA methylation, transcriptomic data analysis, and the integrated analysis of these datasets with proteomic SOMAscan data. RL and CP performed the transcriptomic and NASfinder analyses.; W and JK designed the DNA methylation and transcriptomic analysis and analyzed the NASFinder output data. GT, MPS-B, W, and JK wrote the first draft of the manuscript, and all authors contributed to the writing and reviewed and/or edited the paper. The authors read and approved the final manuscript.

\section{Funding}

This research project was funded by the Nestlé Institute of Health Science.

\section{Availability of data and materials}

The datasets are available on GEO (accession number GSE119539 and GSE119593).

Go to https://www.ncbi.n/m.nih.gov/geo/query/acc.cgi?acc=GSE119593 Go to https://www.ncbi.nlm.nih.gov/geo/query/acc.cgi?acc=GSE119539

Ethics approval and consent to participate

Not applicable

Consent for publication

Not applicable

\section{Competing interests}

JK was employed at Nestle Institute of Health Science during this project and currently works at Vydiant Inc. Nestle and Vydiant are for-profit companies.

GT, W, RL, GTN, GF, PD, SM, CP, and MPS-B have no conflict of interest to report. 


\section{Author details}

${ }^{1}$ The Microsoft Research - University of Trento Centre for Computational and Systems Biology, Piazza Manifattura 1, 38068 Rovereto, Italy. ${ }^{2}$ Department of Mathematics, University of Trento, Via Sommarive 14, 38050 Povo, Italy. ${ }^{3}$ Present address: Department of Experimental Oncology, IEO European Institute of Oncology IRCSS, Milan, Italy. ${ }^{4}$ Division of Systems Biology, National Center for Toxicological Research, FDA, 3900 NCTR Road, Jefferson, AR 72079, USA. ${ }^{5}$ Present Address: Cardiovascular Renal and Metabolism Division of Medlmmune, Astrazeneca, Gaithersburg, MD 20878, USA. ${ }^{6}$ Nestlé Institute of Health Science, Lausanne, Switzerland. 'Department of Computer Science, University of Pisa, Pisa, Italy. ${ }^{8}$ Present Addresses: Vydiant Inc., Folsom, CA 95630, USA. ${ }^{9}$ Present Address: CRCHU de Québec-Université Laval, Quebec City, Québec, Canada.

\section{Received: 2 March 2020 Accepted: 10 November 2020} Published online: 26 November 2020

\section{References}

1. Akalin A, Franke V, Vlahoviček K, et al. Genomation: a toolkit to summarize, annotate and visualize genomic intervals. Bioinformatics. 2015;31:1127-9. https://doi.org/10.1093/bioinformatics/btu775.

2. Allot E, Oliver E, Lysaght J, et al. The SGBS cell strain as a model for the in vitro study of obesity and cancer. Clin Transl Oncol. 2012;14:774-82.

3. Almén MS, Nilsson EK, Jacobsson JA, et al. Genome-wide analysis reveals DNA methylation markers that vary with both age and obesity. Gene. 2014; 548:61-7. https://doi.org/10.1016/j.gene.2014.07.009.

4. Aryee MJ, Jaffe $A E$, Corrada-Bravo $H$, et al. Minfi: a flexible and comprehensive Bioconductor package for the analysis of Infinium DNA methylation microarrays. Bioinformatics. 2014;30:1363-9. https://doi.org/10. 1093/bioinformatics/btu049.

5. Bray GA, Nielsen SJ, Popkin BM. Consumption of high-fructose corn syrup in beverages may play a role in the epidemic of obesity. Am J Clin Nutr. 2004; 79:537-43.

6. Brody $E$, Gold L, Mehan $M$, et al. Life's simple measures: unlocking the proteome. J Mol Biol. 2012;422:595-606. https://doi.org/10.1016/j.jmb.2012 06.021.

7. Bursać BN, Vasiljević AD, Nestorović NM, et al. High-fructose diet leads to visceral adiposity and hypothalamic leptin resistance in male rats - do glucocorticoids play a role? J Nutr Biochem. 2014;25:446-55. https://doi.org/ 10.1016/j.jnutbio.2013.12.005.

8. Campión J, Milagro F, Martínez JA (2010) Chapter 11 - Epigenetics and obesity. In: Progress in Molecular Biology and Translational Science. pp 291-347.

9. Cargnin-Carvalho A, de Mello AH, Bressan JB, et al. Can fructose influence the development of obesity mediated through hypothalamic alterations? J Neurosci Res. 2020;98:1662-8. https://doi.org/10.1002/jnr.24628.

10. Castro AVB, Kolka CM, Kim SP, Bergman RN. Obesity, insulin resistance and comorbidities? Mechanisms of association. Arq Bras Endocrinol Metabol. 2014;58:600-9. https://doi.org/10.1590/0004-2730000003223.

11. Cavill $R$, Jennen D, Kleinjans J, Briedé JJ. Transcriptomic and metabolomic data integration. Brief Bioinform. 2016;17:891-901. https://doi.org/10.1093/ bib/bbv090.

12. Cordero P, Gomez-Uriz AM, Campion J, et al. Dietary supplementation with methyl donors reduces fatty liver and modifies the fatty acid synthase DNA methylation profile in rats fed an obesogenic diet. Genes Nutr. 2013;8:10513. https://doi.org/10.1007/s12263-012-0300-z.

13. Demerath EW, Guan W, Grove ML, et al. Epigenome-wide association study (EWAS) of BMI, BMI change and waist circumference in African American adults identifies multiple replicated loci. Hum Mol Genet. 2015;24:4464-79. https://doi.org/10.1093/hmg/ddv161.

14. Dennis G Jr, Sherman BT, Hosack DA, et al. DAVID: database for annotation, visualization, and integrated discovery. Genome Biol. 2003;4:R60. https://doi. org/10.1186/gb-2003-4-9-r60.

15. Dick KJ, Nelson CP, Tsaprouni L, et al. DNA methylation and body-mass index: a genome-wide analysis. Lancet. 2014;383:1990-8. https://doi.org/10. 1016/S0140-6736(13)62674-4.

16. Dill H, Linder B, Fehr A, Fischer U. Intronic miR-26b controls neuronal differentiation by repressing its host transcript, ctdsp2. Genes Dev. 2012;26: 25-30. https://doi.org/10.1101/gad.177774.111.

17. Du L, Heaney AP. Regulation of adipose differentiation by fructose and GluT5. Mol Endocrinol. 2012;26:1773-82. https://doi.org/10.1210/me.2012-1122.
18. Dunning M, Lynch A, Eldridge M (2016) illuminaHumanv4.db: Illumina HumanHT12v4 annotation data (chip illuminaHumanv4). R package version 1.26.0.

19. Fischer-Posovszky P, Newell FS, Wabitsch M, Tornqvist HE. Human SGBS cells - a unique tool for studies of human fat cell biology. Obes Facts. 2008;1: 184-9. https://doi.org/10.1159/000145784.

20. Gold L, Ayers D, Bertino J, et al. Aptamer-based multiplexed proteomic technology for biomarker discovery. PLoS One. 2010:5. https://doi.org/10. 1371/journal.pone.0015004.

21. Gold L, Walker JJ, Wilcox SK, Williams S. Advances in human proteomics at high scale with the SOMAscan proteomics platform. New Biotechnol. 2011. https://doi.org/10.1016/j.nbt.2011.11.016.

22. Green CR, Wallace M, Divakaruni AS, et al. Branched-chain amino acid catabolism fuels adipocyte differentiation and lipogenesis. Nat Chem Biol. 2016;12:15-21. https://doi.org/10.1038/nchembio.1961.

23. Gustafson DB, Smith U. The WNT inhibitor dickkopf 1 and bone morphogenetic protein 4 rescue adipogenesis in hypertrophic obesity in humans. Diabetes. 2012;61:1217-24. https://doi.org/10.2337/db11-1419.

24. Han J, Denli AM, Gage FH. The enemy within: intronic miR-26b represses its host gene, ctdsp2, to regulate neurogenesis. Genes Dev. 2012;26:6-10. https://doi.org/10.1101/gad.184416.111.

25. Hannou SA, Haslam DE, McKeown NM, Herman MA. Fructose metabolism and metabolic disease. J Clin Invest. 2018;128:545-55. https://doi.org/10. $1172 / J C 196702$.

26. Hansen KD (2016) IlluminaHumanMethylation450kanno.ilmn12.hg19. 1-3.

27. Heinonen S, Buzkova J, Muniandy M, et al. Impaired mitochondrial biogenesis in adipose tissue in acquired obesity. Diabetes. 2015;64:3135-45. https://doi.org/10.2337/db14-1937.

28. Hsu J, Sage J. Novel functions for the transcription factor E2F4 in development and disease. Cell Cycle. 2016;15:3183-90. https://doi.org/10. 1080/15384101.2016.1234551.

29. Hui H, Huang D, McArthur D, et al. Direct spectrophotometric determination of serum fructose in pancreatic cancer patients. Pancreas. 2009;38:706-12. https://doi.org/10.1097/MPA.0b013e3181a7c6e5.

30. Johnson RJ, Sánchez-Lozada LG, Andrews P, Lanaspa MA. Perspective: a historical and scientific perspective of sugar and its relation with obesity and diabetes. Adv Nutr An Int Rev J. 2017;8:412-22. https://doi.org/10.3945/ an.116.014654.

31. Jones PA. Functions of DNA methylation: islands, start sites, gene bodies and beyond. Nat Rev Genet. 2012;13:484-92. https://doi.org/10.1038/ nrg3230.

32. Jones PA. The DNA methylation paradox. The methylation of CpG islands is often equated with transcriptional inactivity and there is overwhelming. Trends Genet. 1999;15:34-7.

33. Khitan Z, Kim DH (2013) Fructose: a key factor in the development of metabolic syndrome and hypertension. 2013:

34. Klip A, Sun Y, Chiu TT, Foley KP. Signal transduction meets vesicle traffic: the software and hardware of GLUT4 translocation. AJP Cell Physiol. 2014;306: C879-86. https://doi.org/10.1152/ajpcell.00069.2014.

35. Koc M, Mayerová V, Kračmerová J, et al. Stress of endoplasmic reticulum modulates differentiation and lipogenesis of human adipocytes. Biochem Biophys Res Commun. 2015;460:684-90. https:/doi.org/10.1016/j.bbrc.2015.03.090.

36. Lê KA, Ith $M$, Kreis $R$, et al. Fructose overconsumption causes dyslipidemia and ectopic lipid deposition in healthy subjects with and without a family history of type 2 diabetes. Am J Clin Nutr. 2009;89:1760-5. https://doi.org/ 10.3945/ajcn.2008.27336.

37. Lee J-E, Schmidt H, Lai B, Ge K. Transcriptional and epigenomic regulation of adipogenesis. Mol Cell Biol. 2019;39:1-20. https://doi.org/10.1128/mcb. 00601-18.

38. Lev Maor G, Yearim A, Ast G. The alternative role of DNA methylation in splicing regulation. Trends Genet. 2015;31:274-80. https://doi.org/10.1016/j. tig.2015.03.002.

39. Lustig RH. Fructose: metabolic, hedonic, and societal parallels with ethanol. YJADA. 2010;110:1307-21. https://doi.org/10.1016/j.jada.2010.06.008.

40. Maksimovic J, Gordon L, Oshlack A. SWAN: subset-quantile within array normalization for Illumina Infinium HumanMethylation450 BeadChips. Genome Biol. 2012;13:R44. https://doi.org/10.1186/gb-2012-13-6-r44.

41. Mariana E, Spera I, Menga A, et al. Glutamine synthetase desensitizes differentiated adipocytes to proinflammatory stimuli by raising intracellular glutamine levels. FEBS Lett. 2014;588:4807-14. https://doi.org/10.1016/j. febslet.2014.11.015. 
42. Medvedeva YA, Khamis AM, Kulakovskiy IV, et al. Effects of cytosine methylation on transcription factor binding sites. BMC Genomics. 2014;15:112. https://doi.org/10.1186/1471-2164-15-119.

43. Meijer K, de Vries M, Al-Lahham S, et al. Human primary adipocytes exhibit immune cell function: adipocytes prime inflammation independent of macrophages. PLoS One. 2011;6. https://doi.org/10.1371/journal.pone.0017154.

44. Milagro Fl, Gómez-Abellán P, Campión J, et al. CLOCK, PER2 and BMAL1 DNA methylation: association with obesity and metabolic syndrome characteristics and monounsaturated fat intake. Chronobiol Int. 2012;29: 1180-94. https://doi.org/10.3109/07420528.2012.719967.

45. Mirmiran P, Yuzbashian E, Asghari G, et al (2015) Consumption of sugar sweetened beverage is associated with incidence of metabolic syndrome in Tehranian children and adolescents. Nutr Metab (Lond) 1-9. doi: https://doi. org/10.1186/s12986-015-0021-6.

46. Münstedt K, Böhme M, Hauenschild A, Hrgovic I. Consumption of rapeseed honey leads to higher serum fructose levels compared with analogue glucose/fructose solutions. Eur J Clin Nutr. 2011;65:77-80. https://doi.org/10. 1038/ejen.2010.186.

47. Muth-köhne E, Westphal-settele K, Brückner J, et al. Linking the response of endocrine regulated genes to adverse effects on sex differentiation improves comprehension of aromatase inhibition in a fish sexual development test. Aquat Toxicol. 2016;176:116-27.

48. Myles IA (2014) Fast food fever: reviewing the impacts of the Western diet on immunity. 1-17.

49. Nagai $M$, Yoneda $Y$, Yoneda $Y$, Yoneda $Y$. Small GTPase ran and ran-binding proteins. Biomol Concepts. 2012;3:307-18. https://doi.org/10.1515/bmc2011-0068.

50. Nassiri I, Lombardo R, Lauria M, et al. Systems view of adipogenesis via novel omics-driven and tissue-specific activity scoring of network functional modules. Sci Rep. 2016a;6. https://doi.org/10.1038/srep28851.

51. Nassiri I, Lombardo R, Lauria M, et al. Systems view of adipogenesis via novel omics-driven and tissue-specific activity scoring of network functional modules. Nat Publ Gr. 2016b:1-19. https://doi.org/10.1038/srep28851.

52. Nilsson E, Jansson PA, Perfilyev A, et al. Altered DNA methylation and differential expression of genes influencing metabolism and inflammation in adipose tissue from subjects with type 2 diabetes. Diabetes. 2014;63: 2962-76. https://doi.org/10.2337/db13-1459.

53. Ohashi K, Munetsuna E, Yamada $\mathrm{H}$, et al. High fructose consumption induces DNA methylation at PPARa and CPT1A promoter regions in the rat liver. Biochem Biophys Res Commun. 2015;468:185-9. https://doi.org/10. 1016/j.bbrc.2015.10.134.

54. Ostroff R, Foreman T, Keeney TR, et al. The stability of the circulating human proteome to variations in sample collection and handling procedures measured with an aptamer-based proteomics array. J Proteome. 2010;73: 649-66. https://doi.org/10.1016/j.jprot.2009.09.004.

55. Pietiläinen $\mathrm{KH}$, Naukkarinen J, Rissanen A, et al. Global transcript profiles of fat in monozygotic twins discordant for BMl: pathways behind acquired obesity. PLoS Med. 2008;5:0472-83. https://doi.org/10.1371/journal.pmed. 0050051.

56. Poppy Roworth A, Ghari F, La Thangue NB. To live or let die - complexity within the E2F1 pathway. Mol Cell Oncol. 2015;2:e970480. https://doi.org/10. 4161/23723548.2014.970480.

57. Robinson MD, Kahraman A, Law CW, et al. Statistical methods for detecting differentially methylated loci and regions. Front Genet. 2014;5:1-7. https:// doi.org/10.3389/fgene.2014.00324.

58. Ron E, Shenkman M, Groisman B, et al. Bypass of glycan-dependent glycoprotein delivery to ERAD by up-regulated EDEM1. Mol Biol Cell. 2011; 22:3945-54. https://doi.org/10.1091/mbc.E10-12-0944.

59. Safe $\mathrm{S}$, Jin $\mathrm{U}-\mathrm{H}$, Hedrick $\mathrm{E}$, et al. Minireview: role of orphan nuclear receptors in cancer and potential as drug targets. Mol Endocrinol. 2014;28:157-72. https://doi.org/10.1210/me.2013-1291

60. Semnani-azad Z, Khan TA, Mejia SB, et al. Association of major food sources of fructose-containing sugars with incident metabolic syndrome. A systematic review and meta-analysis. 2020;3:1-15. https://doi.org/10.1001/ jamanetworkopen.2020.9993.

61. Smith ML, Baggerly KA, Bengtsson H, et al. Illuminaio: an open source IDAT parsing tool for Illumina microarrays. F1000Research 2:264. Doi: 10.12688/ f1000research.2-264.v1. 2013.

62. Smyth GK. Linear models and empirical Bayes methods for assessing differential expression in microarray experiments. Stat Appl Genet Mol Biol. 2004;3:1-26. https://doi.org/10.2202/1544-6115.1027.
63. Stanhope KL, Schwarz JM, Keim NL, et al. Consuming fructose-sweetened, not glucose-sweetened, beverages increase visceral adiposity and lipids and decrease insulin sensitivity in overweight/obese men. J Clin Invest. 2009; 1334:1322-34. https://doi.org/10.1172/JCl37385DS1.

64. Tappy L. Fructose metabolism and noncommunicable diseases: recent findings and new research perspectives. Curr Opin Clin Nutr Metab Care. 2018;21:214-22. https://doi.org/10.1097/MCO.0000000000000460.

65. Tenorio J, Arias P, Martínez-Glez V, et al. Simpson-Golabi-Behmel syndrome types I and II. Orphanet J Rare Dis. 2014;9:138. https://doi.org/10.1186/ s13023-014-0138-0.

66. Tung EWY, Peshdary V, Gagné R, et al (2017) Adipogenic effects and gene expression profiling of Firemaster ${ }^{\oplus} 550$ components in human primary preadipocytes. Environ Health Perspect 125:097013-1:14.

67. van den Dungen M, Murk A, Kok D, Steegenga W. Comprehensive DNA methylation and gene expression profiling in differentiating human adipocytes. J Cell Biochem. 2016;12:1-12. https://doi.org/10.1002/jcb.25568.

68. van den Dungen MW, Murk AJ, Kok DE, Steegenga WT. Persistent organic pollutants alter DNA methylation during human adipocyte differentiation. Toxicol Vitr. 2017;40:79-87. https://doi.org/10.1016/j.tiv.2016.12.011.

69. Varma V, Boros LG, Nolen GT, et al. Fructose alters intermediary metabolism of glucose in human adipocytes and diverts glucose to serine oxidation in the one-carbon cycle energy producing pathway. Metabolites. 2015a;5:364-85.

70. Varma V, László BG, Nolen GT, et al. Metabolic fate of fructose in human adipocytes: a targeted ${ }^{13} \mathrm{C}$ tracer fate association study. Metabolomics. 2015b;11:529-44. https://doi.org/10.1007/s11306-014-0716-0.

71. Voisin S, Almén MS, Zheleznyakova GY, et al. Many obesity-associated SNPS strongly associate with DNA methylation changes at proximal promoters and enhancers. Genome Med. 2015;7:103. https:/doi.org/10.1186/s13073-015-0225-4.

72. Wahjudi PN, Patterson ME, Lim S, et al. Measurement of glucose and fructose in clinical samples using gas chromatography/mass spectrometry. Clin Biochem. 2010:43:198-207. https://doi.org/10.1016/j.clinbiochem.2009.08.028.

73. Wahl S, Drong A, Lehne B, et al. Epigenome-wide association study of body mass index, and the adverse outcomes of adiposity. Nature. 2016. https:// doi.org/10.1038/nature20784

74. Warden CD, Lee H, Tompkins JD, et al. COHCAP: an integrative genomic pipeline for single-nucleotide resolution DNA methylation analysis. Nucleic Acids Res. 2013:41:1-11. https://doi.org/10.1093/nar/gkt242.

75. Wiklund $P$, Zhang $X$, Pekkala $S$, et al. Insulin resistance is associated with altered amino acid metabolism and adipose tissue dysfunction in normoglycemic women. Sci Rep. 2016;6:1-11. https://doi.org/10.1038/srep24540.

76. Wu X, Zhang Y. TET-mediated active DNA demethylation: mechanism, function and beyond. Nat Rev Genet. 2017;18:517-34. https://doi.org/10. 1038/nrg.2017.33.

77. Yang X, Han H, De Carvalho DD, et al. Gene body methylation can alter gene expression and is a therapeutic target in cancer. Cancer Cell. 2014;26: 577-90. https://doi.org/10.1016/j.ccr.2014.07.028.

78. Yao L, Berman B, Farnham P, et al (2016a) ELMER: an R/Bioconductor tool inferring regulatory element landscapes and transcription factor networks using methylomes. 1-19.

79. Yao L, Berman B, Farnham P, et al (2016b) ELMER.data: supporting data for the ELMER package. 1-5.

80. Yao L, Shen $H$, Laird PW, et al. Inferring regulatory element landscapes and transcription factor networks from cancer methylomes. Genome Biol. 2015; 16:105. https://doi.org/10.1186/s13059-015-0668-3.

81. Yeo CR, Agrawal M, Hoon S, et al. SGBS cells as a model of human adipocyte browning: a comprehensive comparative study with primary human white subcutaneous adipocytes. Sci Rep. 2017;7:1-12. https://doi. org/10.1038/s41598-017-04369-2.

82. Zhong J, Krawczyk SA, Chaerkady R, et al. Temporal profiling of the secretome during adipogenesis in humans. J Proteome Res. 2010;9:5228-38. https://doi.org/10.1021/pr100521c.

83. Zubiría MG, Alzamendi A, Moreno G, et al. Long-term fructose intake increases adipogenic potential: evidence of direct effects of fructose on adipocyte precursor cells. Nutrients. 2016;8:198. https://doi.org/10.3390/nu8040198.

\section{Publisher's Note}

Springer Nature remains neutral with regard to jurisdictional claims in published maps and institutional affiliations. 